\title{
Novel carbon fibers synthesis, plasma functionalization, and application to polymer composites
}

\author{
A. Khan ${ }^{1,5^{*}}$, D. Dragatogiannis ${ }^{2}$, P. Jagdale $^{1,3}$, M. Rovere $^{1}$, C. Rosso ${ }^{4}$, A. Tagliaferro $^{1,6}$, \\ C. Charitidis $^{2}$ \\ ${ }^{1}$ Department of Applied Science and Technology (DISAT), Politecnico di Torino, Corso Duca degli Abruzzi, 24, \\ 10129 Torino, Italy \\ ${ }^{2}$ RNanoLab, National Technical University of Athens, School of Chemical Engineering, 9 Heroon Polytechniou St., \\ Zographos, 15780 Athens, Greece \\ ${ }^{3}$ Center for Sustainable Future Technologies @ Polito, Istituto Italiano di Tecnologia, 10129 Torino, Italy \\ ${ }^{4}$ Department of Mechanical and Aerospace Engineering (DIMEAS), Politecnico di Torino, Corso Duca degli Abruzzi, 24 , \\ 10129 Torino, Italy. \\ ${ }^{5}$ Department of Textile Engineering, University of Engineering and Technology, Lahore (Faisalabad Campus), Pakistan \\ ${ }^{6}$ Faculty of Science, University of Ontario Institute of Technology, Oshawa, Ontario, Canada
}

Received 29 June 2020; accepted in revised form 17 September 2020

\begin{abstract}
PAN copolymers were synthesized via a novel technique, atom transfer radical polymerization (ATRP), with the activator generated by electron transfer method (AGET). Carbon fibers (CF) were synthesized at low carbonization temperatures from the novel PAN precursor. Plasma treatment in an oxygen environment at a low pressure of $40 \mathrm{~Pa}$ was carried out for 5 minutes on the $\mathrm{CF}$ at 100 and $200 \mathrm{~W}$ plasma power. The morphology and structure of the CF changed after plasma functionalization, as evident from SEM analysis and Raman spectroscopy. The formation of functional groups like alcohols, carbonyl, and carboxylic on the surface of CF was confirmed with the aid of X-ray photoelectron spectroscopy (XPS) and Fourier transform infrared spectroscopy (FTIR). The wetting test confirmed the higher adhesion of the plasma functionalized CF with the epoxy matrix. Single fiber strength test revealed that plasma functionalized CF retained around $98 \%$ of their original tensile strength. Composites were fabricated from the pristine, and the plasma functionalized CF in 1 and $3 \%$ by weight with epoxy matrix. The surface-modified CF composites depicted improved tensile (23.4\%), tribology (33.62\%), and surface hardness $(11.4 \%)$ properties compared to the composites fabricated from pristine $\mathrm{CF}$.
\end{abstract}

Keywords: polymer composites, carbon fibers, plasma etching, mechanical properties, tribological behavior

\section{Introduction}

Carbon fibers (CF) are marvelous materials that can be employed in various important engineering applications. Carbon fibers possess outstanding physical and chemical properties; for instance, their high tensile strength combined with a low density makes $\mathrm{CF}$ ideal candidates to be employed in high strength low weight structural parts [1]. CFs also possess high resistance to creep, chemicals, and environmental conditions as well. This unique combination of properties has attracted tremendous interest in utilizing the carbon-carbon composites in industries like aerospace, automotive, and building structures [2]. The carbon fiber composites industry thrives at a high pace and will surpass a mammoth demand of 140 ktons in 2020 [1]. At present, the commercial-grade CFs are mostly $70 \%$ by volume, produced from polyacrylonitrile (PAN) filaments that accounts for about $51 \%$ of the total cost of CF production [3]. PAN precursor is preferred for $\mathrm{CF}$ manufacturing due to high 
carbonaceous yield, but the high cost of PAN precursor and high carbonization temperature for the production of commercial-grade $\mathrm{CF}$ has resulted in expensive $\mathrm{CF}$ with limited use in high-end applications $[4,5]$.

Furthermore, PAN precursor production is a hazardous process with negative effects on the environment due to the production of hydrogen cyanide gas [6]. The sharp rise in the demand for CF and the approach of the society towards sustainable processes have encouraged the researchers to look for environment-friendly and cost-effective precursors for commercial grade $\mathrm{CF}$ production $[7,8]$. One approach could be to improve the existing precursor and utilize low carbonization temperatures that can certainly reduce the cost of commercial grade CF $[9,10]$. PAN copolymers with tailored structural properties can be synthesized via a novel technique, atom transfer radical polymerization (ATRP) with the activator generated by electron transfer method (AGET) [3]. The resulting PAN fibers can potentially help in manufacturing the $\mathrm{CF}$ with improved properties at low carbonization temperatures. In recent years a lot of literature is published on the improvement of PAN precursor properties and conversion to $\mathrm{CF}$ at low carbonization temperatures to reduce manufacturing cost and environmental impact $[11,12]$.

The bonding between the CF surface and the matrix plays a key role in achieving the high performances of the carbon fiber composites [13]. For a good adhesion between $\mathrm{CF}$ and polymer matrix, chemical bonding between the matrix and the CF is necessary. Adequate adhesion between the matrix and $\mathrm{CF}$ ensures better load transfer during the application of external stress and consequently improved the performance of the structural components. A good CF surface adhesion in the composite is not achieved by using pristine CF [14]. Instead, weak interphase is formed in the composite, and the performance of $\mathrm{CF}$ reinforced composites is limited $[15,16]$. Various surface treatments are in use to varying the $\mathrm{CF}$ surface, namely sizing, electro-polymerization, heat treatments, nanostructure decoration, chemical functionalization, and surface alteration by plasma radicals $[17,18]$. Plasma treatment is very effective in modifying the surface of CF with several advantages. Firstly, Plasma assisted surface modification is strongly limited to the modification of the first few atomic layers. It exerts a limited influence on the bulk structure of the fibers. This feature is very important since it prevents the risk of altering the mechanical properties of fiber that may degrade its performance. Moreover, the changes on the CF surface by plasma can be applied at low temperatures, even at room temperature that greatly reduces the processing time, the energy required, and the cost of the process [19, 20]. Also, the type of gas employed to generate the plasma radicals is usually an inert gas, e.g., helium, nitrogen, argon, and oxygen. The use of an inert gas reduces not only security issues but also the cost related to the disposal of dangerous chemicals [21]. Several studies have been published by various authors about the enhanced tensile and tribology performances of CF composites after plasma functionalization [22-24]. The objective of this work is to study the plasma functionalization of CF manufactured at low carbonization temperatures from PAN copolymer, synthesized via novel AGET-ATRP method, and their application to composite structures for improved tensile, tribological, and surface hardness properties.

\section{Materials and methods}

\subsection{Raw material}

Poly[(Acrylonitrile)-co-(Itaconic acid)-co-(acrylic acid)] [P(AN-co-IA-co-AC)] was synthesized by copolymerization of Acrylonitrile (AN), Itaconic acid (IA), and Acrylic acid (AC) via redox initiated free radical polymerization. $\mathrm{P}(\mathrm{AN}-\mathrm{co}-\mathrm{IA}-\mathrm{co}-\mathrm{AC})$ was diluted in Dimethylformamide (DMF) solvent at the ratio of $20 \%(\mathrm{w} / \mathrm{v})$ and used as a dope solution. PAN fibers were wet spun using a spinneret of 300 holes with $50 \mu \mathrm{m}$ diameter/ hole. PAN fibers were thermally stabilized in an oxidative environment without prior treatment. Finally, PAN fibers were stabilized in stages, and the profile was set at 190-220-250$270^{\circ} \mathrm{C}$ with a holding time of 4 hours. PAN fibers were carbonized in a two-stage process in an Argon atmosphere, first at $620^{\circ} \mathrm{C}$ for 30 minutes and finally at $1000^{\circ} \mathrm{C}$ for 30 minutes with a fixed heating rate of $5^{\circ} \mathrm{C} / \mathrm{min}$.

\subsection{Plasma treatment}

Plasma Fab 508 equipped with a radiofrequency generator operating at $13.56 \mathrm{MHz}$ was used to carry out the plasma treatment in an oxygen environment at a fixed pressure of $40 \mathrm{~Pa}$ for 5 minutes and plasma powers of 100 and $200 \mathrm{~W}$ respectively. The inside walls of the chamber were cleaned by running the oxygen plasma process at $50 \mathrm{~W}$ prior to the treatment. The CF specimen were plasma treated according to 
the parameters mentioned above and characterized as follows.

\subsection{Analysis of pristine and plasma functionalized CF}

\subsubsection{Surface morphology}

Field Emission Scanning Electron Microscope Merlin (ZEISS) was used to study the morphology of the CF after plasma treatment at various magnifications. The fractured surface of the composites after the tensile analysis was also studied to understand the interaction of the $\mathrm{CF}$ with matrix before and after plasma treatment. A broad magnification range of 10000 to 100000 was selected to study the various specimen.

\subsubsection{Raman spectroscopy}

Raman analysis was performed to study the structure of the CF after plasma treatment. Renishaw Ramanscope H43662 (InVia) instrument equipped with a light source of wavelength $514 \mathrm{~nm}$ was used to carry out the analysis.

\subsubsection{XPS analysis}

The chemical nature and atomic quantity of the functional groups formed after oxygen plasma functionalization was studied by XPS. PHI 5000 Versa Probe instrument (Physical Electronics) equipped with an $\mathrm{Al} \mathrm{K} \alpha$ radiation $(1486.6 \mathrm{eV}) \mathrm{X}$-ray was used to carry out the XPS analysis. The photoelectron signal of high resolution (HR) and the survey spectra were collected by using a spot size of $100 \mu \mathrm{m}$ at a pass energy value of 23.5 and $187.85 \mathrm{eV}$, respectively. Multipack 9.6 software was used to deconvolute the various spectra to obtain the atomic compositions of the various functional groups.

\subsubsection{FTIR-ATR analysis}

The chemical nature of the functional groups was further examined using an Equinox 44 (Bruker) FTIR-ATR instrument. The analysis was carried out by diluting the pristine and plasma-treated $\mathrm{CF}$ in the $\mathrm{KBr}$ pellet in the frequency range of 1000 to $4000 \mathrm{~cm}^{-1}$. A total of 64 scans at $4 \mathrm{~cm}^{-1}$ resolution were carried out for all the samples.

\subsubsection{Wetting test}

The adhesion of the plasma functionalized CF to the matrix was studied via a simple wetting test. 2.5 inches in length of the pristine and plasma functionalized
$\mathrm{CF}$ were cut and weighed before being submerged into the epoxy (Hexion Resin, RIM 135) for 5 minutes and hanged in the ambient. The wetted specimen was weighed after an interval of 1 and 24 hours, respectively. The quantity of the epoxy retained by the pristine and the plasma functionalized CF was calculated and compared. 5 specimens in each category were studied to ensure reproducibility.

\subsubsection{Single fiber strength study}

The tensile analysis on the single carbon filament was performed to study the effects of the plasma functionalization on the breaking strength. The average diameter of the CF was $6.86+0.50$ microns, as determined by SEM. 20 samples in each category were measured using an electronic single fiber strength tester at a gauge length of $25 \mathrm{~mm}$, a strain rate of $1 \mathrm{~mm} / \mathrm{min}$, and a load cell of $2 \mathrm{~N}$.

\subsection{Composite preparation}

CFs were shredded in short size with the aid of an industrial pulverizer BB90E (Savatec) and dispersed in the pre-determined weight percentage in the epoxy matrix. Ultra-Turrax T18, an overhead mixer, was used to disperse the $\mathrm{CF}$ in the matrix. A curing agent was added, and the mixture was subjected to further blending. Sonication was carried out in Elmasonic $(\mathrm{S} 15 \mathrm{H})$ instrument for 15 minutes to release the entrapped air bubbles followed by additional degassing for 20 minutes at a pressure of $50 \mathrm{mbar}$ in the vacuum chamber to eliminate the air bubbles completely from the mixture. The mixture was cured in an oven for at $60^{\circ} \mathrm{C}$ for 4 hours $[25,26]$. Dog-bone shape samples were fabricated for the tensile analysis according to the ASTM D 638-04 standard. Tribology and surface hardness analyses were carried out on $25 \mathrm{~mm} \times 25 \mathrm{~mm} \times 5 \mathrm{~mm}$ plates. 5 specimens for various concentrations in each category of the abovementioned analysis were fabricated to ensure reproducibility.

\subsection{Analysis of the composites}

1. The tensile performance of the composites was measured with a Q-test 10 mechanical tester (MTS). The dog bone specimen in each category was subjected to tensile force using a $10 \mathrm{kN}$ load cell and a strain rate of $1 \mathrm{~mm} / \mathrm{min}$ throughout the analysis. Stress and strain values were deduced from the load elongation curves received from the instrument and plotted in origin 9.0 software. The 
tensile behavior of the resin, pristine CF composites, and the plasma-treated CF composites were compared among one another.

2. Friction and wear resistance were measured by Pin-on-Disk (Anton-Paar) tribometer. A steel ball (AISI 420) $6 \mathrm{~mm}$ in diameter was employed in the tribology test. All specimens were analyzed using a constant $5 \mathrm{~N}$ normal load; the linear speed set a $185 \mathrm{~mm} / \mathrm{sec}$ and $3.27 \mathrm{~mm}$ reciprocating amplitude. The coefficient of friction $(\mu)$ and the specific wear rate $\left(W_{\mathrm{r}}\right)$ were calculated as shown in Equations (1) and (2):

$$
\begin{aligned}
& \mu=\frac{F_{\mathrm{f}}}{F_{\mathrm{n}}} \\
& W_{\mathrm{r}}=\frac{\Delta m}{L \cdot \rho \cdot F_{\mathrm{n}}}
\end{aligned}
$$

where $F_{\mathrm{f}}$ is the friction force parallel to the sliding surfaces, $F_{\mathrm{n}}$ is the normal load, $\rho$ is the density $\left[\mathrm{g} / \mathrm{cm}^{3}\right]$ of the specimen, $L$ is the sliding distance, and $\Delta m[\mathrm{~g}]$ is the mass loss after the test.

3. Surface hardness was measured with Durometer Shore A instrument according to the ASTM standard D-2240. Specimens were placed on a flat surface of the iron plate as the standard background and measured on the four corners and at the center.

\section{Results and discussions}

\subsection{Surface morphology of pristine and plasma functionalized $\mathbf{C F}$}

The surface of the plasma functionalized CF shows pits and canals as compared to pristine CF, see Figure 1a. CF treated at the plasma power of $100 \mathrm{~W}$, 5 minutes show a lesser amount of surface abrasion

compared to the $200 \mathrm{~W}$ for 5 minutes samples where the surface abrasion and formation of new surfaces are more visible (Figure $1 \mathrm{~b}$ and $1 \mathrm{c}$ ). The changes in the fiber surface morphology are in accordance with literature reported on the plasma modification of CF. The new surfaces formed after plasma functionalization can increase the adhesion with the matrix and improve the tensile and tribology performance of the composites [22, 27].

\subsection{XPS analysis}

The atomic percentage of oxygen on the surface of the CF increases after plasma functionalization, as reported in Table 1. The atomic percentage of the surface oxygen 1st increases on the surface of the $\mathrm{CF}$ and then starts to decrease as we double the plasma power for the same treatment time, as illustrated in Figure 2. The reason for this trend is explained in the morphology analysis, where it can be seen clearly that at higher treatment power, the top layers were ablated, exposing the bottom, less functionalized layers of the CF. Similar trends were noted in the O/C ratios, which decreased as the plasma power increases, and opposite trends were observed in the $\mathrm{N} / \mathrm{C}$ ratios as the ablation of the top layers exposed higher nitrogen-containing core of the $\mathrm{CF}$. The atomic percentage of all the elements identified by the survey spectra are reported in Table 1.

Table 1. Elemental composition from survey spectra on pristine and plasma-treated CFs with 5\% mean deviation in atomic \%age.

\begin{tabular}{|l|c|c|c|c|c|}
\hline \multicolumn{1}{|c|}{ Sample id } & C1s & O1s & N1s & O/C & N/C \\
\hline Pristine CF & 87.0 & 11.0 & 2.0 & 0.126 & 0.023 \\
\hline $100 \mathrm{~W}, 5 \mathrm{~min}$ & 75.0 & 21.9 & 3.1 & 0.28 & 0.041 \\
\hline $200 \mathrm{~W}, 5 \mathrm{~min}$ & 80.0 & 16.0 & 4.0 & 0.20 & 0.050 \\
\hline
\end{tabular}

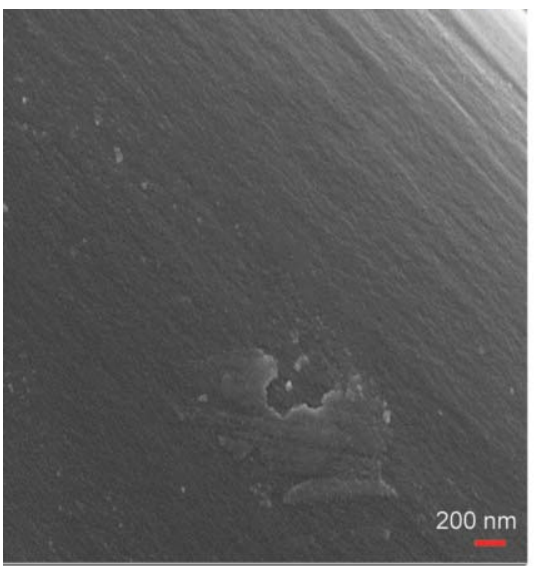

a)

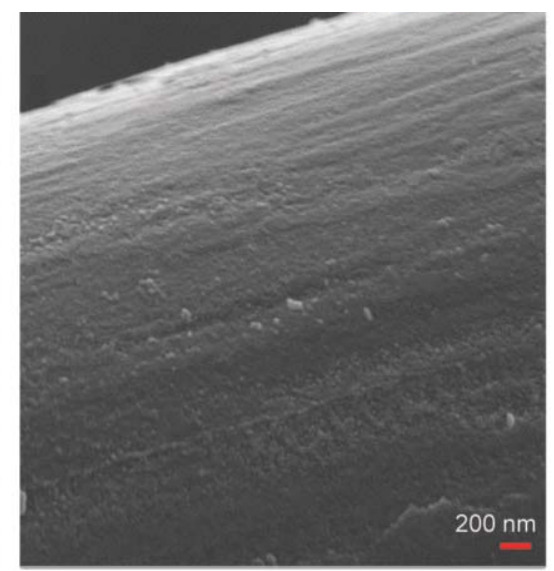

b)

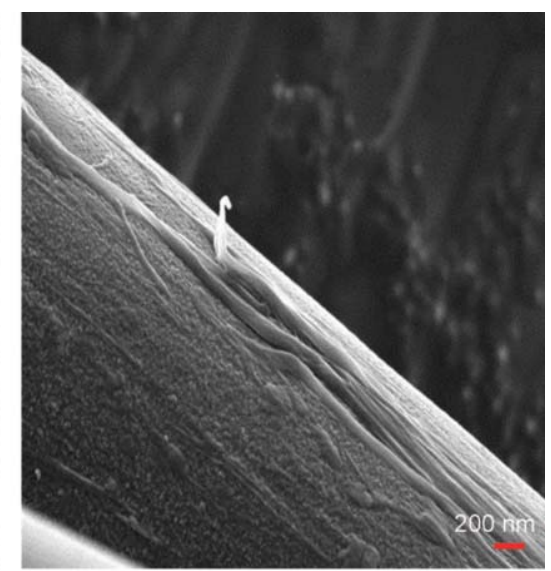

c)

Figure 1. Morphology of (a) pristine, (b) plasma modified CF, $100 \mathrm{~W}$, (c) $200 \mathrm{~W}$, at $100000 \times$ magnification. 

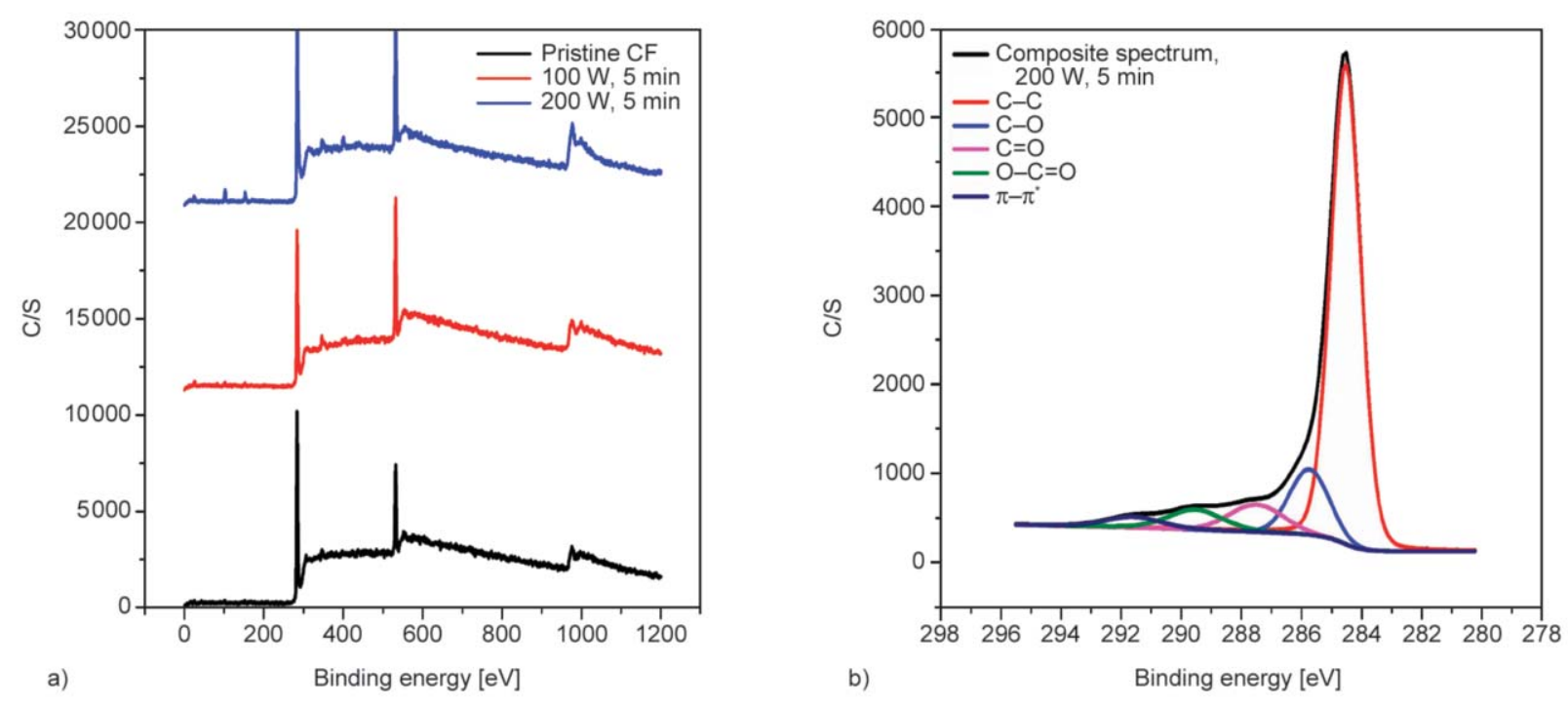

Figure 2. (a) Survey spectra, (b) C1s high resolution spectra of the $200 \mathrm{~W}, 5$ min specimen.

Table 2. Functional groups comparison from H.R C1s spectra on PAN-based pristine and plasma-treated CFs with $5 \%$ mean deviation in atomic $\%$.

\begin{tabular}{|l|r|r|c|c|c|}
\hline \multicolumn{1}{|c|}{ Sample id } & $\mathbf{C}-\mathbf{C}$ & $\mathbf{C}-\mathbf{O}$ & $\mathbf{C}=\mathbf{O}$ & $-\mathbf{O}-\mathbf{C}=\mathbf{O}$ & $\boldsymbol{\pi}-\boldsymbol{\pi}^{*}$ \\
\hline Pristine CF & 72.74 & 7.43 & 8.27 & 5.00 & 6.56 \\
\hline $100 \mathrm{~W}, 5$ min & 61.72 & 21.77 & Weak signal & 15.35 & 1.16 \\
\hline $200 \mathrm{~W}, 5$ min & 68.34 & 13.51 & 7.88 & 6.31 & 3.96 \\
\hline
\end{tabular}

The atomic percentage of the various components in the high-resolution spectra $\mathrm{C} 1 \mathrm{~s}$ was extracted by the curve fitting (Table 2). C1s spectra of each specimen were deconvoluted using Gaussian-Lorentzian sum function of 4 curves. The chemical shift was assigned according to the Briggs chemical shift table [28]. The high-resolution spectra confirm the presence of alcohols $(\mathrm{C}-\mathrm{O})$ and carboxylic $(\mathrm{O}-\mathrm{C}=\mathrm{O})$ groups in higher quantity after plasma functionalization on the surface of the CF. These groups are responsible for the interaction with the epoxy matrix, which enhances the tensile, tribology, and surface hardness performance of the CF polymer composites [23, 27].

\subsection{Raman analysis}

Raman analysis of the CF before and after plasma modification is reported in Figure 3. The characteristic D- and G-peaks of carbon materials are exhibited by the pristine and plasma-treated CF in Raman spectra. Both D- and G-peaks were fitted with GaussianLorentzian shaped function to estimate the areas under the peaks. The $I_{\mathrm{D}} / I_{\mathrm{G}}$ ratio, which is a measure of the degree of disorder in a material $[29,30]$, was calculated by the ratio of area under the D and G-peaks, respectively. The $I_{\mathrm{D}} / I_{\mathrm{G}}$ ratios of the various specimens

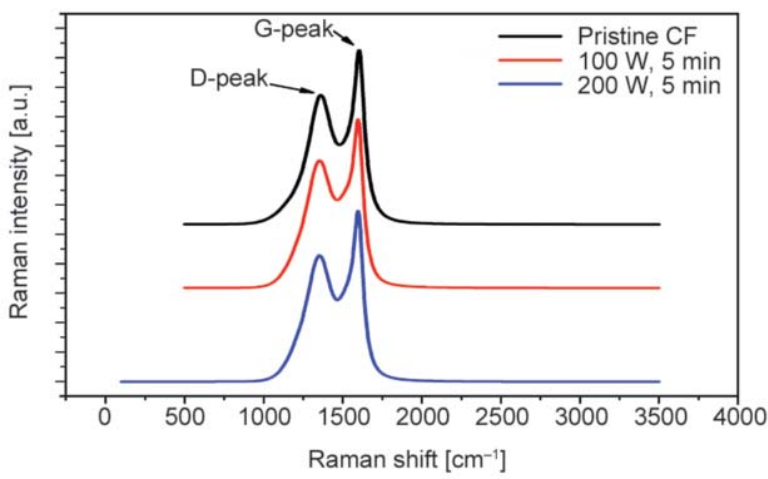

Figure 3. Raman analysis of pristine and plasma modified CF.

are reported in Table 3. The plasma-treated CF shows a higher $I_{\mathrm{D}} / I_{\mathrm{G}}$ ratio, i.e., a higher degree of disorder. This behavior can be explained by the morphology analysis and the XPS analysis, where the formation of functional groups after plasma treatment changes the morphology and the crystalline structure of carbon fibers that lead to a relatively higher degree of disorder. A marginal decrease in disorder in the $200 \mathrm{~W}$ sample can be explained by the SEM images (Figure 1c) where the ablation of top layers exposed the more ordered structure of carbon fibers. An increase in the carbon content, as evident from the XPS

Table 3. $I_{\mathrm{D}} / I_{\mathrm{G}}$ ratio comparison, D and G-peak positions of the various $C F$.

\begin{tabular}{|c|l|c|c|c|}
\hline \multirow{2}{*}{ S/no. } & \multirow{2}{*}{ Sample Id. } & \multicolumn{2}{|c|}{$\begin{array}{c}\text { Peak position } \\
{\left[\mathbf{c m}^{-1}\right]}\end{array}$} & \multirow{2}{*}{$\boldsymbol{I}_{\mathbf{D}} / \mathbf{I}_{\mathbf{G}}$} \\
\cline { 3 - 4 } & & $\mathbf{D}$ & $\mathbf{G}$ & \\
\hline 1 & Pristine CF & 1359 & 1605 & 1.83 \\
\hline 2 & $100 \mathrm{~W}, 5 \mathrm{~min}$ & 1351 & 1599 & 1.954 \\
\hline 3 & $200 \mathrm{~W}, 5 \mathrm{~min}$ & 1351 & 1600 & 1.939 \\
\hline
\end{tabular}


analysis (see Tables 1, and 2), further solidifies our argument. The effects of plasma treatment reported in our study are conformance with the ones reported in the literature. Montes-Morán et al., [31] and Wen et al., [32] reported a similar trend in the degree of disorder of commercial carbon fibers after plasma treatment.

\subsection{FTIR-ATR analysis}

The absorbance spectra of various $\mathrm{CF}$ are depicted in Figure 4. The oxygen-containing species formed due to the plasma functionalization were identified according to Infrared and Raman Characteristic Group Frequencies [33]. The peak with center at $1650 \mathrm{~cm}^{-1}$ wave number corresponds to the carbonyl $(\mathrm{C}=\mathrm{O})$ bond from unsaturated Ketones/Aldehydes. A weak band can be seen in the spectra of the plasma functionalized CF with the center at $1460 \mathrm{~cm}^{-1}$. This peak can be attributed to the $\mathrm{C}-\mathrm{O}$ stretching and/or the $\mathrm{O}-\mathrm{H}$ deformation of the carboxylic acid functional

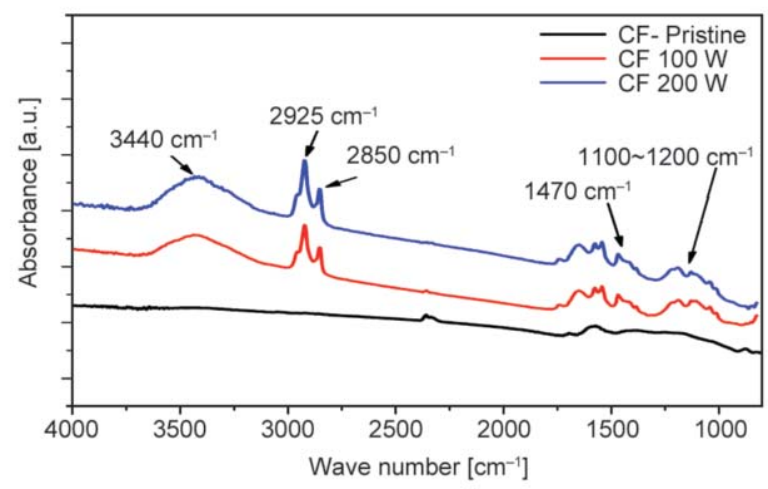

Figure 4. FTIR-ATR analysis of pristine and plasma functionalized $\mathrm{CF}$.

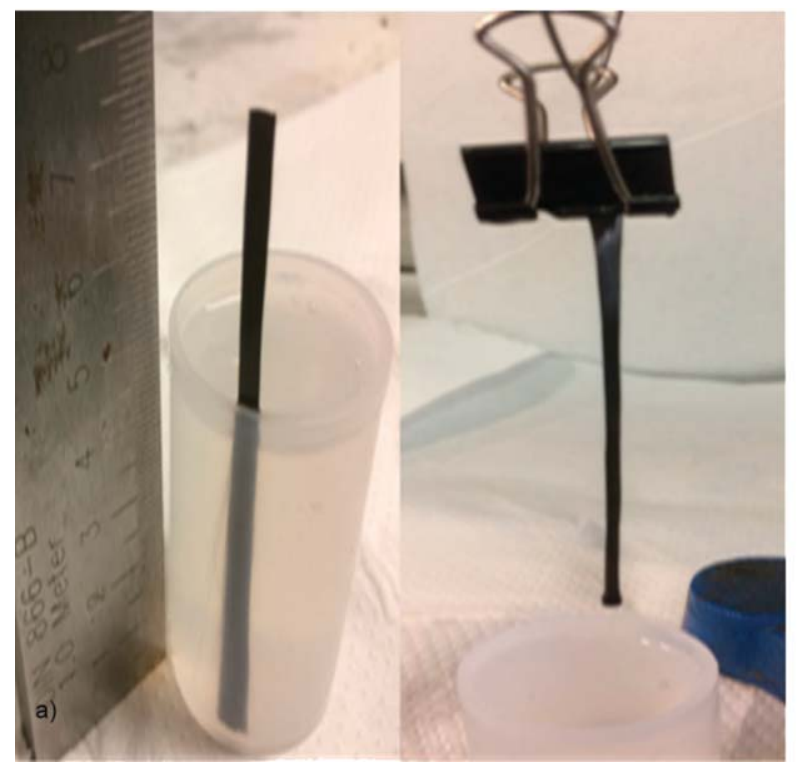

group that was confirmed in the XPS analysis. The formation of $-\mathrm{O}-\mathrm{C}=\mathrm{O}$ and $-\mathrm{OH}$ groups on the $\mathrm{CF}$ surface was further confirmed by the peak with a center at $3440 \mathrm{~cm}^{-1}$, which is the characteristic peak of the carboxylic acid group. The double peak with centers at 2850 and $2925 \mathrm{~cm}^{-1}$ is associated with the $\mathrm{OH}$ stretching of the carboxylic acid. The formation of chemical species like $\mathrm{C}-\mathrm{O}, \mathrm{C}=\mathrm{O}$, and $\mathrm{O}-\mathrm{C}=\mathrm{O}$ on the surface of $\mathrm{CF}$ after plasma treatment is in conformance to the published literature on the subject [34]. The functional groups on the CF surface are responsible for higher adhesion with the matrix (see wetting test) and contribute to improved composite performance.

\subsection{Wetting test}

In the wetting test, the plasma functionalized CF depicts a higher affinity to the epoxy resin, as shown in Figure 5. The plasma-treated CF at the treatment power of 100 and $200 \mathrm{~W}$ show 22 and $24 \%$ epoxy pick up after 1 hour, respectively. After 24 hours, the epoxy retention remained higher compared to the pristine $\mathrm{CF}$, i.e., 14 and $15 \%$ respectively for the 100 and $200 \mathrm{~W}$ specimens. The higher retention of the resin is due to the formation of oxygen-containing chemical species and new surfaces after plasma functionalization (see XPS and SEM analysis). The formation of new surfaces like crevices, pits, and canals on the plasma-treated CF favored more surface contact points with the matrix and thus higher pick up of the resin compared to the pristine CF. Similar behavior has been reported in one of our

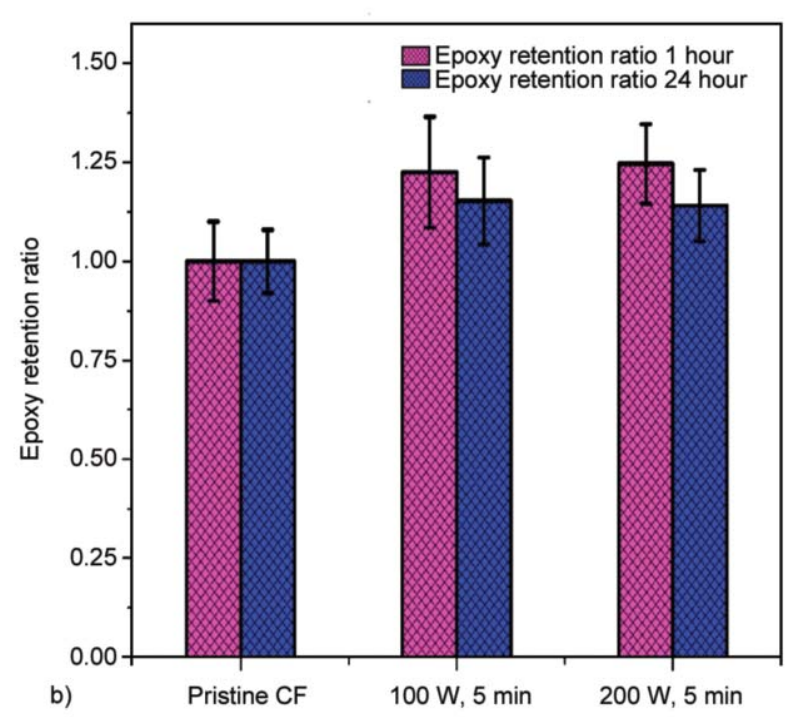

Figure 5. Wettability test on the pristine and plasma functionalized CF, a) methodolgy, b) comparison. 
previous papers on the plasma functionalization of cotton-based CF [35].

\subsection{Single fiber strength}

The plasma-treated CF shows a slight loss in the single fiber strength after the treatment. The $100 \mathrm{~W}$, 5 min sample shows a decline of a mere $0.86 \%$ in the tensile strength while the $200 \mathrm{~W}$ samples losses slightly more tensile strength, around $1.72 \%$, compared to the pristine CF. This reduction in tensile strength is minimal and statistically not significant. Generally, the carbon fiber should not lose more than $15 \sim 20 \%$ of the original tensile strength after any surface treatment for better performance of the composite structure $[36,37]$. So the results we obtained are in accordance with the threshold set for the application of surface modified CF in polymer composites. The slightly higher loss in the $200 \mathrm{~W}$ sample is probably due to the severe action of the plasma radicals, as evident from the morphology analysis (Figure 1c). Results for mean values of 20 samples for each category of pristine and plasma-treated CF are displayed in Figure 6.

\subsection{Tensile properties}

The tensile analysis of the pristine and the plasma functionalized CF composites is depicted in Figure 7. We can see that the resin shows a maximum loadbearing capacity of 51.2 MPa. Reinforcement with pristine $\mathrm{CF}$ enhances the load-bearing capacity and induces a slight plastic behavior in the matrix.

The ultimate tensile strength recorded for pristine $\mathrm{CF}$ reinforced composites was around $57.7 \mathrm{MPa}$, i.e. the reinforcement of the matrix with pristine $\mathrm{CF}$ at $3 \%$ filler loading enhances its load-bearing capacity by $12.5 \%$. The composites fabricated with the plasmatreated CF show higher tensile strength in comparison

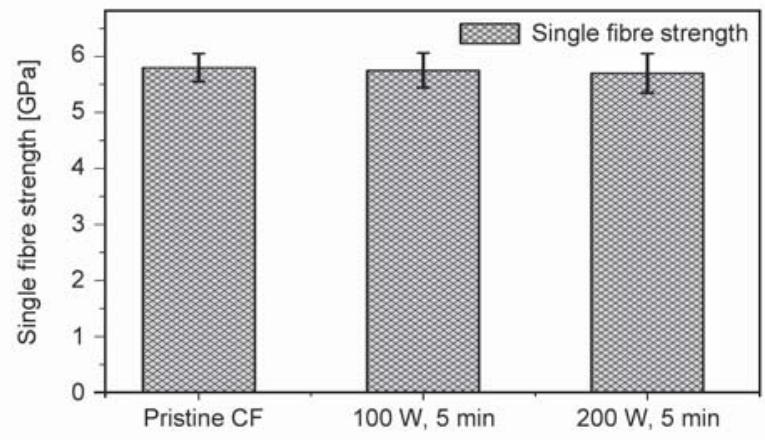

Figure 6. Single fiber strength comparison of pristine and plasma functionalized $\mathrm{CF}$. to the matrix itself and pristine CF composites. Load-bearing capacity of 70.5 and $71.5 \mathrm{MPa}$ is shown by the composites fabricated with CF $100 \mathrm{~W}$ and CF $200 \mathrm{~W}$ specimen, respectively, at 3\% filler loading by weight. Some important tensile properties deduced from the stress vs. strain curves also showed significant changes. The ultimate tensile strength (UTS) of the composites fabricated from the plasma functionalized CF depicts a significant increase in comparison to the composites of pristine $\mathrm{CF}$ and blank resin. The CF $200 \mathrm{~W}$ sample depicts an increase in the UTS of $38.7 \%$ compared to blank epoxy and $23.9 \%$ in comparison to the pristine CF composites at the same weightage $(3 \%)$ of the filler. Similar behavior was observed in the resilience studies where an increase of load-bearing capacity in the elastic zone was depicted by the both pristine $\mathrm{CF}$ composites and the plasma functionalized $\mathrm{CF}$ composites when compared to matrix. An increase of $23 \%$ in resilience was recorded in the case of pristine CF composites at $3 \%$ weightage of the filler used. The plasma functionalized $\mathrm{CF}$ showed even higher capacity to resist deformation in the elastic zone i.e. an increase of $43.4 \%$ was recorded for the specimen CF 200 at the $3 \%$ weightage of filler when compared to the resin and $16 \%$ more than the pristine CF composites as depicted in Figure 8.

Reinforcing the resin with pristine and plasma functionalized $\mathrm{CF}$ enhanced the ductility comparing to the brittle matrix, as shown in Figure 9a. The plasma functionalized fibers further increased the tensile toughness of the composite. The highest values of tensile toughness were shown by the specimens CF 1003 and CF 200-3, which were $86 \%$ and $81 \%$ higher than the blank resin, respectively. These tensile properties improved without significantly compromising

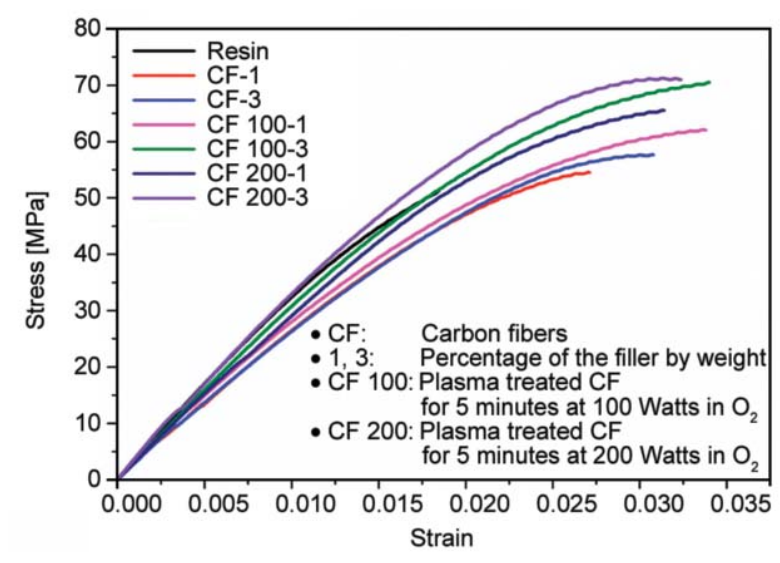

Figure 7. Stress $v s$. strain behavior of the composites fabricated from pristine and plasma functionalized CF. 

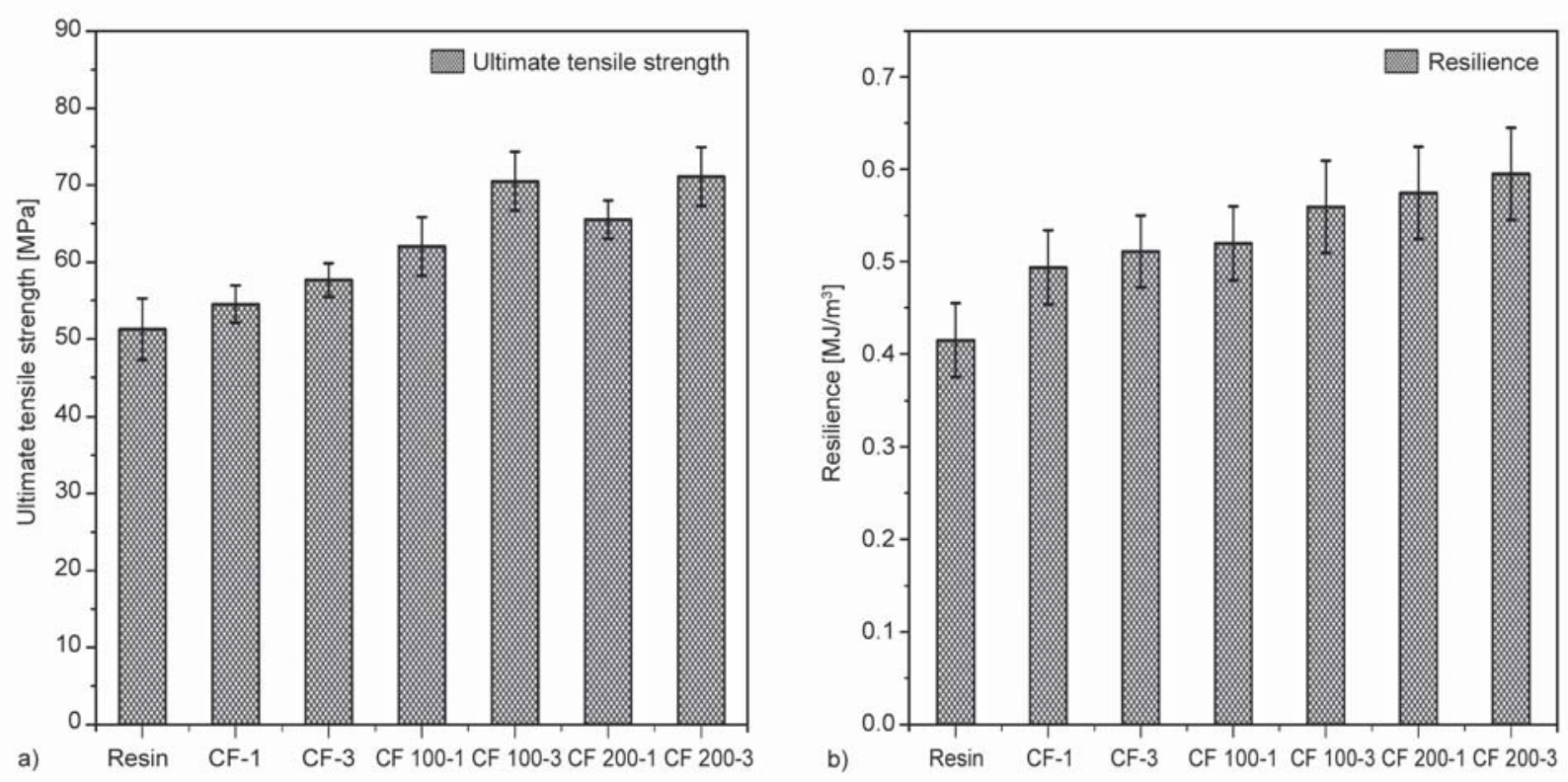

Figure 8. (a) Tensile strength and (b) Resilience comparison $b / w$ resin, pristine and plasma functionalized CF composites.

the young modulus of the epoxy resin, as depicted in Figure 9b. Composites fabricated with plasma functionalized CF show further enhancement in the overall load-bearing capacity with no or negligible alteration in the stiffness of the epoxy matrix.

The better tensile performance of the plasma functionalized CF composites is due to the higher adhesion with the epoxy matrix at the interface. The high interfacial adhesion of the plasma functionalized $\mathrm{CF}$ with the epoxy matrix is a twofold process. Firstly, the morphology of the CF changed after the plasma treatments, and new surfaces (pits and crevices) were formed (see Figure 1b, 1c). These new surfaces

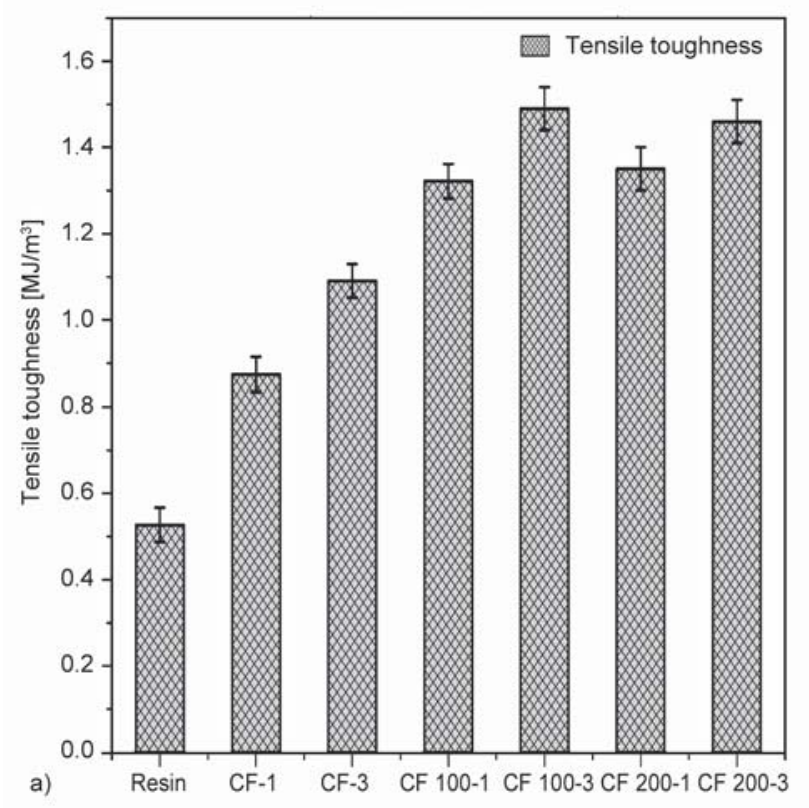

ensured a better wetting and higher surface contact of the CF with the matrix that led to higher mechanical interlocks between the $\mathrm{CF}$ and the matrix [38, 39]. Furthermore, the formation of chemical species $(\mathrm{C}-\mathrm{O}, \mathrm{C}=\mathrm{O}$, and $\mathrm{COOH})$ after oxygen plasma functionalization, increased the surface energy and active sites on the surface of CF, which facilitated a higher degree of wetting of CF surface by the matrix by reducing the surface tension and helped to form chemical bonds with the matrix. This phenomenon ultimately led to enhanced interfacial adhesion between the $\mathrm{CF}$ and the surrounding matrix [40, 41]. Higher adhesion between the plasma functionalized $\mathrm{CF}$, and

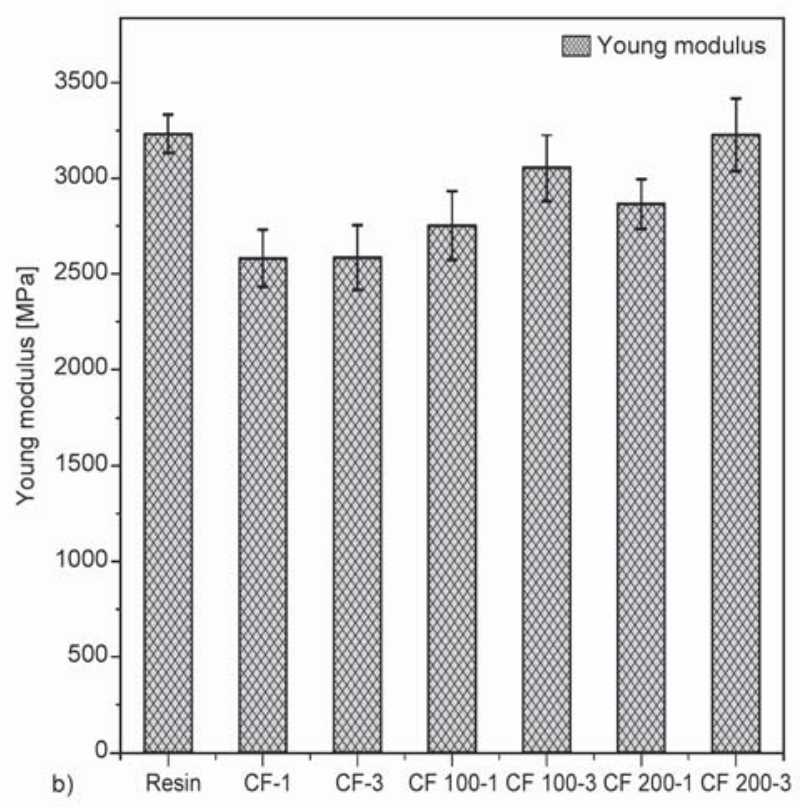

Figure 9. (a) Toughness and (b) stiffness comparison b/w matrix, pristine, and plasma functionalized CF composites. 


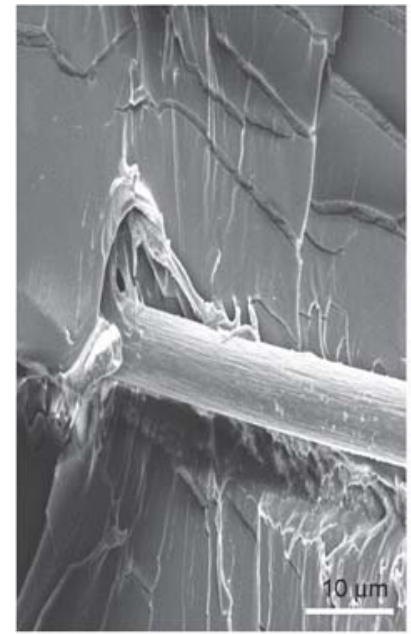

a)

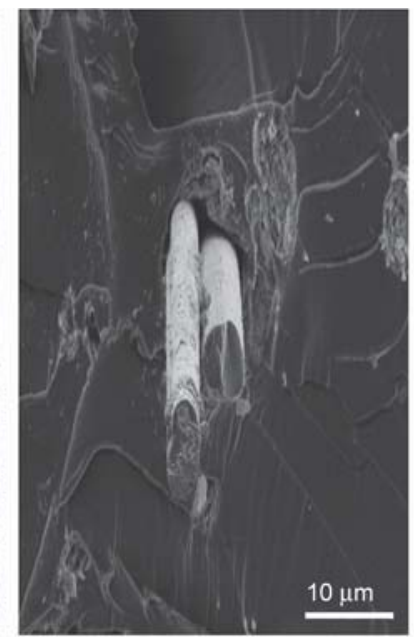

b)

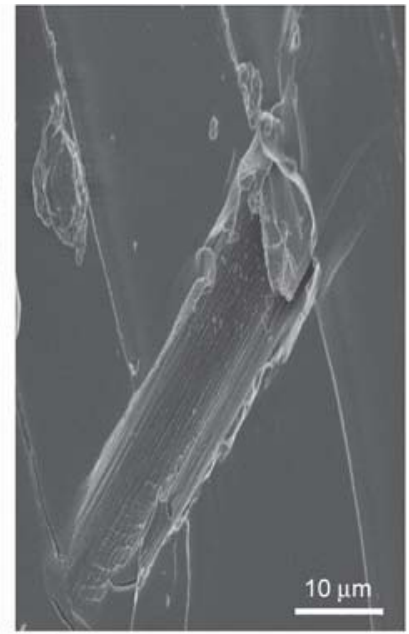

c)

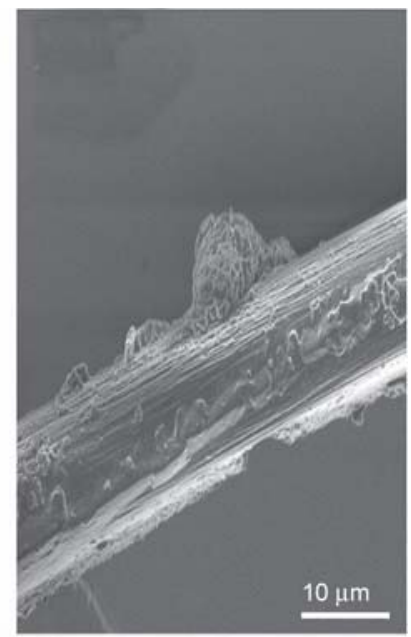

d)

Figure 10. Dispersion and interaction of the plasma functionalized CF with the matrix. a) CF 100-1, b) CF 100-3, c) CF 200-1, d) CF 200-3.

the matrix at the interface provided an adequate stress transfer through the matrix and reduced the localized stress concentration at the fiber/matrix interface, resulting in an enhanced ability of the composite structure to withstand the applied tensile load [42, 43]. Similar findings have been reported in the literature by Al-Saleh et al. [44], Pittmann et al. [24] and Jimenez et al. [45], which further consolidates our argument. The enhanced tensile performance of plasma functionalized $\mathrm{CF}$ can further be attributed to the uniform dispersion of the CF in the epoxy resin. Uniform dispersion of the filler in the matrix reduces the stress concentration centers and improves the uniformity of stress distribution during the application of tensile loads [46]. As evident from Figure 10, the CFs are homogeneously dispersed in the epoxy matrix in an unbundled state and are extending between the matrix layers (Figure 10a, 10b). Dispersion to a single fiber state enhanced the physical bonds with the matrix and provided more mechanical locking points in the matrix by the fibers, which ultimately led to higher tensile properties [47]. The CF extending between the matrix layers anchored the applied stress by retarding the crack onset and accumulation as well as obstructing the layer slippage of the polymer matrix [48]. The enhanced tensile properties of the plasma functionalized CF composites can further be explained by the stress transfer mechanisms such as micromechanical interlocking (see Figure 10), chemical bonds (see XPS, FTIR analysis and wetting test), and a marginal contribution from weak Van der Waals forces between the matrix and the CF. Allaoui et al. [49] and Bai and Allaoui [50] have confirmed the role of stress transfer mechanisms in enhancing the mechanical performances of the polymer composites owing to efficient stress distribution and blocking of the polymer layer slippage in the event of load application. The addition of the plasma functionalized CF may have increased the cross-linking in the polymer matrix. A higher degree of cross-linking in the matrix blocks the molecular motion and improves its robustness [51, 52], though further investigation is necessary to ascertain this phenomena.

\subsection{Friction and specific wear rate analysis}

In the friction and wear analysis, the blank resin depicts a large mass loss and a high coefficient of friction (Figure 11). A high mass loss was recorded at the end of the analysis due to the surface damage by the steel ball contact (Figure 12a). The coefficient of friction was marginally reduced by the addition of $1 \%$ by weight of the pristine $\mathrm{CF}$, but the surface of the composite still depicted a lot of deterioration and, consequently, a high mass loss (Figure 10b). The addition of a higher amount of the pristine $\mathrm{CF}(3 \mathrm{wt} \%)$ reduced the friction co-efficient by $13 \%$, i.e., 1.13 from 1.3 and the mass loss to some extent, i.e., $18 \%$ compared to the blank resin. Composites fabricated from the plasma functionalized CF significantly improved the resistance against the frictional force and surface abrasion. The specimens CF 100-3 and CF 200-3 exhibited a reduction of the friction co-efficient to 35 and $40 \%$, respectively, as compared to the blank matrix along with a higher ability to resist the surface damage, i.e., 36 and $43.6 \%$ decrease in specific wear rate (Figure 11b).

Functionalized carbon fibers composites with improved tribological properties have been reported in 

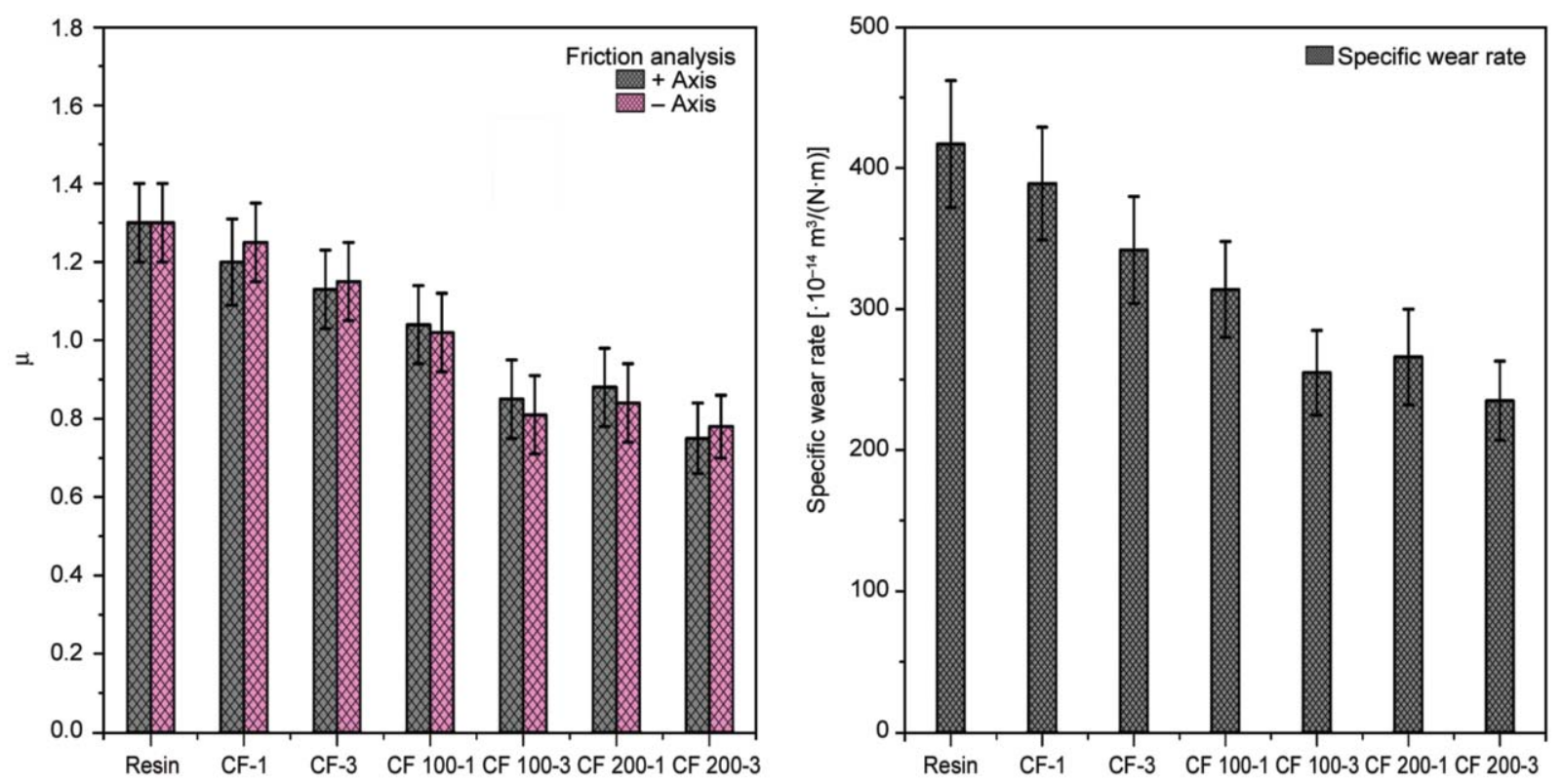

Figure 11. (a) Friction analysis (b) specific wear rate comparison of the pristine and plasma functionalized CF composites.

the literature by several authors. Kim et al. [53] and Rhee et al. [22] have reported the enhanced friction and wear performance of the oxygen plasma-treated $\mathrm{CF}$ composites. They attributed the improved properties to better interfacial adhesion of the CF with the matrix owing to the functional groups formed on the CF surface after plasma functionalization. The interfacial adhesion between the $\mathrm{CF}$ and the matrix is improved in two ways. Firstly, the formation of the new surfaces ensured higher wetting of the CF by the matrix and resulted in a higher number of van der Waals bonds between the matrix and the CF [54]. Secondly, the functional groups formed after plasma treatment helped to form chemical bonds with the epoxy matrix that led to better protection of the matrix by the
CF in the event of abrasion by the steel ball [55]. Our findings in XPS, FTIR analysis, and wetting test support these views. Additionally, the higher mechanical properties of the composites lead to higher friction and wear resistance [56]. The plasma functionalized CFs were dispersed to single fiber level in the matrix (Figure 10) that also played its role in enhancing the tribological properties. Dispersion to single fiber level ensured the availability of more fibers at the interface, especially in case of a higher amount of filler in the matrix that led to better load transfer by the $\mathrm{CF}$ at the contact point with the steel ball during the analysis [57] and saved the matrix from deterioration by acting as a spacer between the steel ball and the matrix. Schon [58] reported the similar behavior of

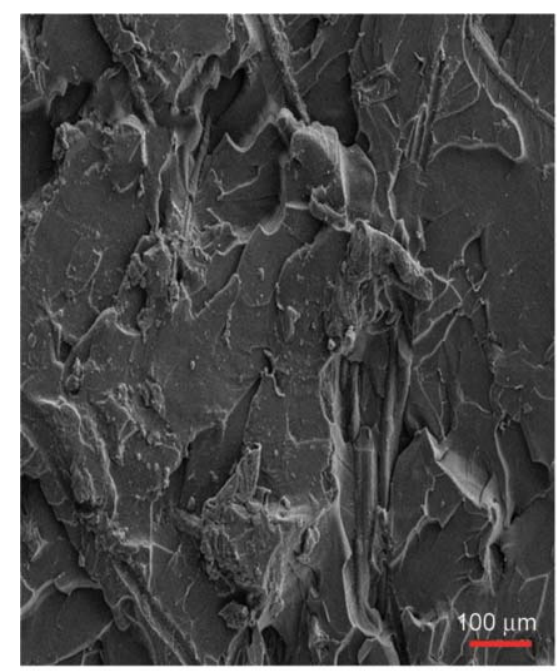

a)

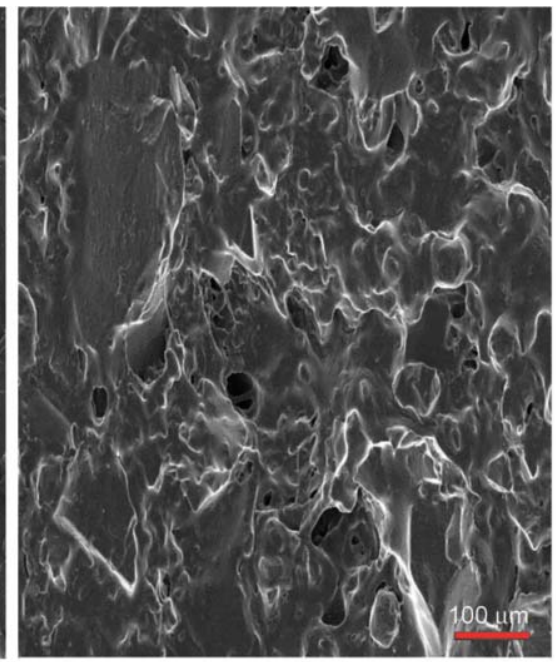

b)

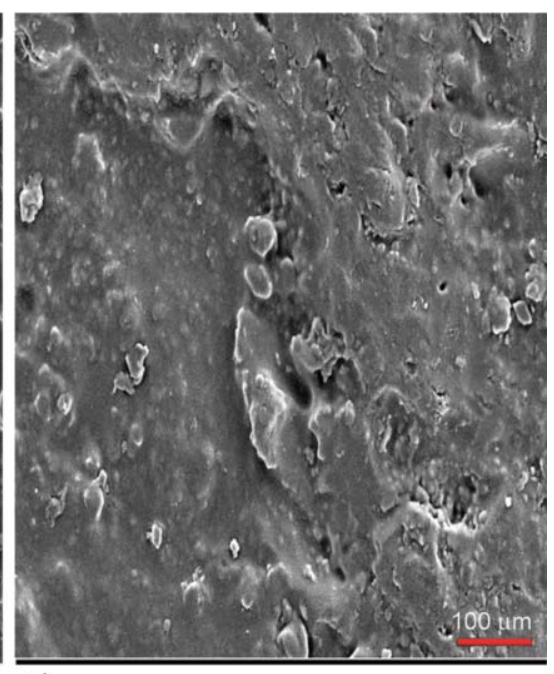

c)

Figure 12. Morphology of the friction specimen, (a) resin, (b) pristine, (c) plasma functionalized CF composites. 
CF in epoxy composites for improved tribological performance. The self-lubricating ability of the $\mathrm{CF}$ may also have contributed to reducing the friction coefficient [57]. Micro melting as a result of friction heat and mechanical deterioration was visible on the surfaces of all the composite specimens, though the magnitude of the surface damage varies among different specimens. The surface of the pristine $\mathrm{CF}$ composites exhibited a high surface deterioration after friction analysis (Figure 12b) that resulted into a high mass loss, while the plasma functionalized CF better protected the matrix from damage by the steel ball during the analysis due to higher adhesion with the matrix at the interface $[53,55]$ as depicted in Figure 12c.

\subsection{Hardness measurement}

The mean hardness value for blank epoxy resin was recorded to be 75 Shore A. Surface hardness marginally increased after the addition of $1 \mathrm{wt} \%$ of the pristine CF. Further increase in the loading (3 wt\%) of CFs increased the hardness to 79 Shore A i.e. 5.3\% more than the blank resin. This behavior can be attributed to the $\mathrm{CF}$, which are stiffer than the epoxy matrix. Reinforcing the epoxy matrix with plasma functionalized CFs further increases the hardness. The best results were shown by the specimen CF 200-3 where a mean value of hardness 88 Shore A was recorded, which is $17.3 \%$ more than the blank resin (Figure 13).

Although sufficient literature wasn't found on this subject some articles do report the enhanced hardness properties of CNTs/ epoxy composites [57]. The increase in hardness of the plasma functionalized CF composites can be due to the increase in the cross-linking and stacking that, in turn, reduces the molecular

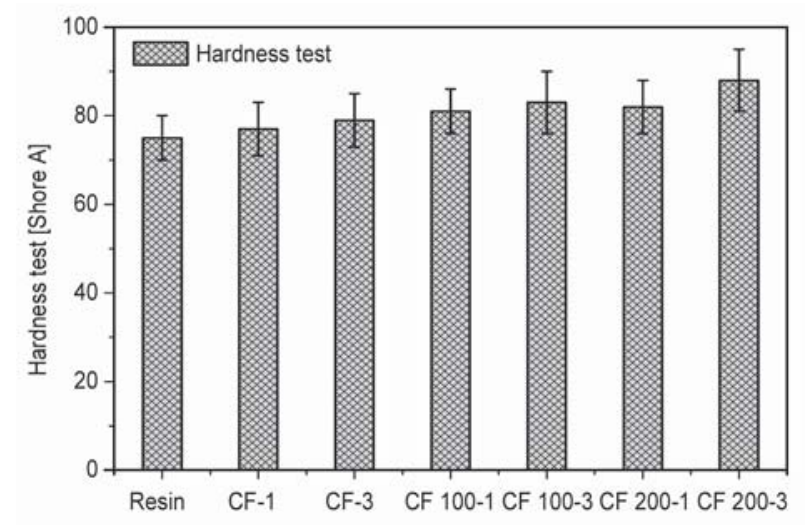

Figure 13. Hardness comparison of resin, pristine, and plasma functionalized CF composites. movement in the polymer [59] and thus make the polymer more resistant to penetration by the indenter. Further research is needed in this area to have a better insight into the mechanisms responsible for this behavior.

\section{Conclusions}

In conclusion, we found that low-pressure plasma treatment in an oxygen environment is an effective and suiTable technique to modify the novel CF surface. With proper tuning of the plasma variables, we can ensure that the CF retain more than $98 \%$ of their original tensile strength, which is a key factor for the performance of the composite structure. XPS and FTIR analysis results confirmed the formation of functional groups like alcohols, ethers, and carboxylic acid on the surface of the CF after plasma functionalization. The wettability test further strengthened our argument of enhanced interfacial adhesion with the matrix after the plasma functionalization, which is a key factor in the high performance of the composites. Application of the plasma-treated $\mathrm{CF}$ to the epoxy composites showed enhanced tensile, tribology, and surface hardness properties, which further supports our recommendations to use low-pressure oxygen plasma treatment for the functionalization of novel carbon fibers.

\section{Acknowledgements}

The authors extend their gratitude to Pietro Mandracci for ensuring the availability of Plasma Fab508, Micaela Castellino for XPS measurements, Mauro Raimondo for SEM images, Marcello Cazzulo for epoxy resin provision, ORIC/ 105-ASRB/3116 grant, and EU. FP7 Project 'FIBRALSPEC', grant agreement no. 604248 for financial assistance. Notes: The authors declare no competing financial interest.

\section{References}

[1] Park S-J., Lee S-Y.: History and structure of carbon fibers. in 'Carbon fibers' (ed.: Park S-J.). Springer, Dordrecht, Vol 210, 1-30 (2015).

https://doi.org/10.1007/978-94-017-9478-7_ 1

[2] Wu X., Zhao J., Rao X., Chung D. D. L.: Carbon fiber epoxy-matrix composites with hydrothermal-carboncoated halloysite nanotube filler exhibiting enhanced strength and thermal conductivity. Polymer Composites, 41, 2687-2703 (2020).

https://doi.org/10.1002/pc.25567 
[3] Soulis S., Anagnou S., Milioni E., Mpalias E., Kartsonakis I. A., Kanellopoulou I., Markakis V., Koumoulos E. P., Kontou E., Charitidis C. A.: Strategies towards novel carbon fiber precursors: The research results on the synthesis of PAN copolymers via AGET ATRP and on lignin as a precursor. Nano World Journal, 1, 88-94 (2015). https://doi.org/10.17756/nwj.2015-011

[4] Zhou X., Wang P., Zhang Y., Zhang X., Jiang Y.: From waste cotton linter: A renewable environment-friendly biomass based carbon fibers preparation. ACS Sustainable Chemistry and Engineering, 4, 5585-5593 (2016). https://doi.org/10.1021/acssuschemeng.6b01408

[5] Salim N. V., Blight S., Creighton C., Nunna S., Atkiss S., Razal J. M.: The role of tension and temperature for efficient carbonization of polyacrylonitrile fibers: Toward low cost carbon fibers. Industrial and Engineering Chemistry Research, 57, 4268-4276 (2018).

https://doi.org/10.1021/acs.iecr.7b05336

[6] Jagdale P., Koumoulos E. P., Cannavaro I., Khan A., Castellino M., Dragatogiannis D. A., Tagliaferro A., Charitidis C. A.: Towards green carbon fibre manufacturing from waste cotton: A microstructural and physical property investigation. Manufacturing Review, 4, 10/1-10/9 (2017). https://doi.org/10.1051/mfreview/2017008

[7] Khan A., Jagdale P., Rovere M., Nogués M., Rosso C., Tagliaferro A.: Carbon from waste source: An ecofriendly way for strengthening polymer composites. Composites Part B: Engineering, 132, 87-96 (2018). https://doi.org/10.1016/j.compositesb.2017.08.016

[8] Kawasaki N., Tominaga H., Ogata F., Inoue K., Kankawa M.: Development of novel carbon fiber produced from waste fiber by cabonization. Journal of Oleo Science, 61, 593-600 (2012). https://doi.org/10.5650/jos.61.593

[9] Liu J., Xiao S., Shen Z., Xu L., Zhang L., Peng J.: Study on the oxidative stabilization of polyacrylonitrile fibers by microwave heating. Polymer Degradation and Stability, 150, 86-91 (2018).

https://doi.org/10.1016/j.polymdegradstab.2018.02.017

[10] Liu J., Zhang C., Guo S., Xu L., Xiao S., Shen Z.: Microwave treatment of pre-oxidized fibers for improving their structure and mechanical properties. Ceramics International, 45, 1379-1384 (2019). https://doi.org/10.1016/j.ceramint.2018.08.311

[11] Zhang C., Li R., Liu J., Guo S., Xu L., Xiao S., Shen Z.: Hydrogen peroxide modified polyacrylonitrile-based fibers and oxidative stabilization under microwave and conventional heating - The 1st comparative study. Ceramics International, 45, 13385-13392 (2019). https://doi.org/10.1016/j.ceramint.2019.04.035

[12] Qiao M., Kong H., Ding X., Hu Z., Zhang L., Cao Y., Yu M.: Study on the changes of structures and properties of PAN fibers during the cyclic reaction in supercritical carbon dioxide. Polymers, 11, 402/1-402/12 (2019).

https://doi.org/10.3390/polym11030402
[13] Johnston J., Koo B., Subramanian N., Chattopadhyay A.: Modeling the molecular structure of the carbon fiber/ polymer interphase for multiscale analysis of composites. Composites Part B: Engineering, 111, 27-36 (2017). https://doi.org/10.1016/j.compositesb.2016.12.008

[14] Srivastava V., Zamperlin N., Fox B., Pegoretti A.: Effect of carbonization and multi-walled carbon nanotubes on polyacrylonitrile short carbon fiber-epoxy composites. Polymer Composites, 39, E817-E825 (2018). https://doi.org/10.1002/pc.24252

[15] Yuan X., Zhu B., Cai X., Zhao S., Qiao K., Zhang M.: Effects of particle size and distribution of the sizing agent on carbon fiber/epoxy composites interfacial adhesion. Polymer Composites, 39, E2036-E2045 (2018). https://doi.org/10.1002/pc.24439

[16] Kainourgios P., Kartsonakis I. A., Dragatogiannis D. A., Koumoulos E. P., Goulis P., Charitidis C. A.: Electrochemical surface functionalization of carbon fibers for chemical affinity improvement with epoxy resins. Applied Surface Science, 416, 593-604 (2017). https://doi.org/10.1016/j.apsusc.2017.04.214

[17] Zhao M., Meng L., Ma L., Wu G., Wang Y., Xie F., Huang Y.: Interfacially reinforced carbon fiber/epoxy composites by grafting melamine onto carbon fibers in supercritical methanol. RSC advances, 6, 29654-29662 (2016). https://doi.org/10.1039/C6RA00570E

[18] Yang S., Chalivendra V., Benjamin E., Kim Y.: Electrical response of novel carbon nanotubes embedded and carbon fiber $\mathrm{z}$-axis reinforced jute/epoxy laminated composites. Polymer Composites, 40, E1189-E1198 (2019). https://doi.org/10.1002/pc.24935

[19] Feih S., Schwartz P.: Modification of the carbon fiber/ matrix interface using gas plasma treatment with acetylene and oxygen. Journal of Adhesion Science and Technology, 12, 523-539 (1998). https://doi.org/10.1163/156856198X00209

[20] Cuesta A., Dhamelincourt P., Laureyns J., MartinezAlonso A., Tascón J. M. D.: Effect of various treatments on carbon fiber surfaces studied by Raman microprobe spectrometry. Applied Spectroscopy, 52, 356-360 (1998). https://doi.org/10.1366/0003702981943815

[21] Silva L. L. G., Santos A. L., Nascente P. A. P., Kostov K. G.: Atmospheric plasma treatment of carbon fibers for enhancement of their adhesion properties. Journal of Physics: Conference Series, 511, 012082/1-012082/7 (2014). https://doi.org/10.1088/1742-6596/511/1/012082

[22] Rhee K. Y., Park S. J., Hui D., Qiu Y.: Effect of oxygen plasma-treated carbon fibers on the tribological behavior of oil-absorbed carbon/epoxy woven composites. Composites Part B: Engineering, 43, 2395-2399 (2012). https://doi.org/10.1016/j.compositesb.2011.11.046 
[23] Ma K., Chen P., Wang B., Cui G., Xu X.: A study of the effect of oxygen plasma treatment on the interfacial properties of carbon fiber/epoxy composites. Journal of Applied Polymer Science, 118, 1606-1614 (2010). https://doi.org/10.1002/app.32549

[24] Pittman C. U., Jiang W., He G-R., Gardner S. D.: Oxygen plasma and isobutylene plasma treatments of carbon fibers: Determination of surface functionality and effects on composite properties. Carbon, 36, 25-37 (1998). https://doi.org/10.1016/S0008-6223(97)00147-4

[25] Pravin J., Khan A. A., Massimo R., Carlo R., Alberto T.: Multiwalled carbon nanotube - Strength to polymer composite. Physical Sciences Reviews, 1, 20150009/120150009/15 (2016).

https://doi.org/10.1515/psr-2015-0009

[26] Khan A., Savi P., Quaranta S., Rovere M., Giorcelli M., Tagliaferro A., Rosso C., Jia C. Q.: Low-cost carbon fillers to improve mechanical properties and conductivity of epoxy composites. Polymers, 9, 642/1-642/14 (2017). https://doi.org/10.3390/polym9120642

[27] Gallo S. C., Charitidis C., Dong H.: Surface functionalization of carbon fibers with active screen plasma. Journal of Vacuum Science and Technology A, 35, 021404/1-021404/10 (2017).

https://doi.org/10.1116/1.4974913

[28] Briggs D., Beamson G.: Primary and secondary oxygen-induced $\mathrm{C} 1 \mathrm{~s}$ binding energy shifts in X-ray photoelectron spectroscopy of polymers. Analytical Chemistry, 64, 1729-1736 (1992).

https://doi.org/10.1021/ac00039a018

[29] Ryoo D., Kim J. Y., Duy P., Cho S. H., Chung H., Yoon T. H.: Fast and non-destructive Raman spectroscopic determination of multi-walled carbon nanotube (MWCNT) contents in MWCNT/polydimethylsiloxane composites. Analyst, 143, 4347-4353 (2018). https://doi.org/10.1039/C8AN00351C

[30] Afanasyeva N. I., Jawhari T., Klimenko I. V., Zhuravleva T. S.: Micro-Raman spectroscopic measurements on carbon fibers. Vibrational Spectroscopy, 11, 79-83 (1996). https://doi.org/10.1016/0924-2031(95)00063-1

[31] Montes-Morán M., Young R.: Raman spectroscopy study of high-modulus carbon fibres: Effect of plasmatreatment on the interfacial properties of single-fibreepoxy composites: Part II: Characterisation of the fibre-matrix interface. Carbon, 40, 857-875 (2002). https://doi.org/10.1016/S0008-6223(01)00207-X

[32] Wen H-C., Yang K., Ou K-L., Wu W-F., Chou C-P., Luo R-C., Chang Y-M.: Effects of ammonia plasma treatment on the surface characteristics of carbon fibers. Surface and Coatings Technology, 200, 3166-3169 (2006). https://doi.org/10.1016/j.surfcoat.2005.07.036

[33] Sokrates G.: Infrared and Raman characteristic group frequencies: Tables and charts. Wiley, Chichester (2004).
[34] Park S-J., Chang Y-H., Moon C-W., Suh D-H., Im SS., Kim Y-C.: A study of atmospheric plasma treatment on surface energetics of carbon fibers. Bulletin of the Korean Chemical Society, 31, 335-338 (2010). https://doi.org/10.5012/bkcs.2010.31.02.335

[35] Khan A., Jagdale P., Castellino M., Rovere M., Jehangir Q., Mandracci P., Rosso C., Tagliaferro A.: Innovative functionalized carbon fibers from waste: How to enhance polymer composites properties. Composites Part B: Engineering, 139, 31-39 (2018). https://doi.org/10.1016/j.compositesb.2017.11.064

[36] Li R., Ye L., Mai Y-W.: Application of plasma technologies in fibre-reinforced polymer composites: A review of recent developments. Composites Part A: Applied Science and Manufacturing, 28, 73-86 (1997). https://doi.org/10.1016/S1359-835X(96)00097-8

[37] Scheffler C., Wölfel E., Förster T., Poitzsch C., Kotte L., Mäder G.: Influence of microwave plasma treatment on the surface properties of carbon fibers and their adhesion in a polypropylene matrix. IOP Conference Series: Materials Science and Engineering, 139, 012046/1012046/8 (2016).

https://doi.org/10.1088/1757-899x/139/1/012046

[38] Dilsiz N.: Plasma surface modification of carbon fibers: A review. Journal of Adhesion Science and Technology, 14, 975-987 (2000). https://doi.org/10.1163/156856100743013

[39] Böhm R., Thieme M., Wohlfahrt D., Wolz D., Richter B., Jäger H.: Reinforcement systems for carbon concrete composites based on low-cost carbon fibers. Fibers, 6, 56/1-56/21 (2018). https://doi.org/10.3390/fib6030056

[40] Corujeira-Gallo S., Dong H.: Effect of microstructure on the plasma surface treatment of carbon fibres. Journal of Composite Materials, 51, 3239-3256 (2017). https://doi.org/10.1177/0021998316684935

[41] Pizzorni M., Lertora E., Gambaro C., Mandolfino C., Salerno M., Prato M.: Low-pressure plasma treatment of CFRP substrates for epoxy-adhesive bonding: An investigation of the effect of various process gases. The International Journal of Advanced Manufacturing Technology, 102, 3021-3035 (2019).

https://doi.org/10.1007/s00170-019-03350-9

[42] Ronghao L., Keqiang L., Haiyong T., Jianmin X., Shaoquan L.: Mechanical properties of plasma-treated carbon fiber reinforced PTFE composites with CNT. Surface and Interface Analysis, 49, 1064-1068 (2017). https://doi.org/10.1002/sia.6278

[43] Yuan H., Wang C., Zhang S., Lin X.: Effect of surface modification on carbon fiber and its reinforced phenolic matrix composite. Applied Surface Science, 259, 288293 (2012).

https://doi.org/10.1016/j.apsusc.2012.07.034

[44] Al-Saleh M. H., Sundararaj U.: Review of the mechanical properties of carbon nanofiber/polymer composites. Composites Part A: Applied Science and Manufacturing, 42, 2126-2142 (2011).

https://doi.org/10.1016/j.compositesa.2011.08.005 
[45] Jimenez G. A., Jana S. C.: Oxidized carbon nanofiber/ polymer composites prepared by chaotic mixing. Carbon, 45, 2079-2091 (2007). https://doi.org/10.1016/j.carbon.2007.05.015

[46] Coleman J. N., Khan U., Gun'ko Y. K.: Mechanical reinforcement of polymers using carbon nanotubes. Advanced Materials, 18, 689-706 (2006). https://doi.org/10.1002/adma.200501851

[47] Tiwari S., Bijwe J.: Surface treatment of carbon fibers - A review. Procedia Technology, 14, 505-512 (2014). https://doi.org/10.1016/j.protcy.2014.08.064

[48] Zhu J., Kim J., Peng H., Margrave J. L., Khabashesku V. N., Barrera E. V.: Improving the dispersion and integration of single-walled carbon nanotubes in epoxy composites through functionalization. Nano Letters, $\mathbf{3}$, 1107-1113 (2003). https://doi.org/10.1021/n10342489

[49] Allaoui A., Bai S., Cheng H. M., Bai J. B.: Mechanical and electrical properties of a MWNT/epoxy composite. Composites Science and Technology, 62, 1993-1998 (2002). https://doi.org/10.1016/S0266-3538(02)00129-X

[50] Bai J. B., Allaoui A.: Effect of the length and the aggregate size of MWNTs on the improvement efficiency of the mechanical and electrical properties of nanocomposites - Experimental investigation. Composites Part A: Applied Science and Manufacturing, 34, 689-694 (2003). https://doi.org/10.1016/S1359-835X(03)00140-4

[51] Frankland S. J. V., Caglar A., Brenner D. W., Griebel M.: Molecular simulation of the influence of chemical cross-links on the shear strength of carbon nanotubepolymer interfaces. The Journal of Physical Chemistry B, 106, 3046-3048 (2002).

https://doi.org/10.1021/jp015591+

[52] Godara A., Mezzo L., Luizi F., Warrier A., Lomov S. V., van Vuure A. W., Gorbatikh L., Moldenaers P., Verpoest I.: Influence of carbon nanotube reinforcement on the processing and the mechanical behaviour of carbon fiber/ epoxy composites. Carbon, 47, 2914-2923 (2009). https://doi.org/10.1016/j.carbon.2009.06.039
[53] Kim S. S., Yu H. N., Lee D. G., Murayama H., Kageyama K.: Tribological behaviors of plasma-treated carbon composite grooved surfaces. Composite Structures, 92, 1039-1046 (2010). https://doi.org/10.1016/j.compstruct.2009.09.052

[54] Wenxia W.: Plasma treatment of carbon fiber on the tribological property of polyimide composite. Surface and Interface Analysis, 49, 682-686 (2017). https://doi.org/10.1002/sia.6208

[55] Cui L-J., Geng H-Z., Wang W-Y., Chen L-T., Gao J.: Functionalization of multi-wall carbon nanotubes to reduce the coefficient of the friction and improve the wear resistance of multi-wall carbon nanotube/epoxy composites. Carbon, 54, 277-282 (2013). https://doi.org/10.1016/j.carbon.2012.11.039

[56] Zhang L. C., Zarudi I., Xiao K. Q.: Novel behaviour of friction and wear of epoxy composites reinforced by carbon nanotubes. Wear, 261, 806-811 (2006). https://doi.org/10.1016/j.wear.2006.01.033

[57] Dong B., Yang Z., Huang Y., Li H-L.: Study on tribological properties of multi-walled carbon nanotubes/epoxy resin nanocomposites. Tribology Letters, 20, 251-254 (2005). https://doi.org/10.1007/s11249-005-8637-8

[58] Schön J.: Coefficient of friction and wear of a carbon fiber epoxy matrix composite. Wear, 257, 395-407 (2004). https://doi.org/10.1016/j.wear.2004.01.008

[59] Rafique I., Kausar A., Muhammad B.: Epoxy resin composite reinforced with carbon fiber and inorganic filler: Overview on preparation and properties. Polymer-Plastics Technology and Engineering, 55, 16531672 (2016). https://doi.org/10.1080/03602559.2016.1163597 